\title{
Continental collision and the tectono-sedimentary evolution of forelands
}

\author{
Editors: G. Bertotti (Amsterdam), K. Schulmann (Prague), S. Cloetingh (Amsterdam)
}

During the (UN)COUPLED2000 Meeting (Amsterdam, 31 August - 2 September 2000) more than one hundred geoscientists from European and non-European countries have met to discuss the geology of continental collision zones and their influence on the evolution of foredeeps and forelands. More than 100 presentations were given both in oral and poster format.

The fundamental idea inspiring the Meeting was to discuss the interactions between colliding continental lithospheric plates. Already from the initial stages it was recognized that only an approach able to integrate the three components of the system, namely the orogen, the foredeep and the foreland, could cover the entire width of the topic. A very important role is played by the orogen itself, which can be strong, thereby enabling an efficient mechanical coupling between the two converging plates or weak thereby accommodating most of the convergence. In the first case, stress is directly transmitted and deformation is exported over large distances far into the forelands. In the second case, stress cannot be transmitted to the foreland easily and strain is mainly concentrated in the neighborhood of the orogen itself. The foredeep, like other sedimentary basins, is of great importance because it stores information on horizontal and vertical movements in the region and surroundings. The strength and the stress state of orogen vary through time, so that it may be strong at the beginning of convergence, weaken during thickening and thermal relaxation and subsequently harden again at the end of orogenesis. Thus, the foreland structures can be reactivated during various stages of strong mechanical coupling and may offer good record of such episodes.

The invitation made by the organizers has been taken over by most of the participants and the word (Un)Coupled was frequently mentioned. Interestingly enough, the concept of coupling was investigated and discussed under different, often original perspectives, sometimes different from the ones originally foreseen by the organizers. As an example, vertical coupling between the upper and lower crust and/or between crust and upper mantle received substantial attention. Indeed, such mechanical relations are important in control- ling the response of forelands to the events in the collisional zone.

A significant proportion of the contributions presented at the (UN)COUPLED2000 was expanded and is now included in this Special Publication of the European Geosiences Union.

A number of papers have investigated theoretical aspects of collision dynamics and foreland deformation. Garfunkel et al. addressing the very core of the Meeting discuss interactions between orogen evolution and the sedimentary record of the foredeep basin. Following this approach, sedimentary patterns in the basin can be diagnostic for events taking place in the adjacent orogen. Ziegler et al. analyze a large number of case studies and detect systematic patterns in the geological record with stages of "soft" collision characterized by the confinement of deformation in the orogen and "strong" stages when structures at several hundreds of kilometres away from the orogen were reactivated. The relevance of regional compilations is demonstrated by such studies. Tikoff et al. and Teyssier et al. analyze the role of vertical coupling between lithospheric layers in general and in wrench zones. It is apparent that such relations bear fundamental consequences also in the way continental collision and foreland deformation take place. Indeed, the importance of coupling/decoupling states between lithospheric layers is increasingly being recognized as of major importance in controlling the behaviour of plates and the expression of deformation visible in seismics and in the field. Ježek et al. present a modeling study of the deformation field associated with oblique continental collision, a situation common in several orogens.

A wide set of papers was dedicated to the Carpathians and their foreland demonstrating how the interest in this part of the world is very strong with new ideas being developed and new techniques applied. Konečný et al. present an updated synthesis of the geological evolution of the entire system inclusive of the Carpathians and the Pannonian basin.The role of slab retreat and mantle dynamics are clearly indicated. Deformation patterns in the Carpathian belt have been 
investigated by Hrouda et al. using magnetic anisotropy studies. Patterns of deformation and reactivation during the Carapthian orogeny have been analyzed by Gotowała and Hałuszczak, and Krzywiec. In both cases, there are clear relations between events in the foreland and events in the collisional domain. The contribution by Francu et al. presents an analysis of vertical movements and erosional episodes taking place in front of the foredeep of the eastern termination of the Variscan belt. Vertical movements and the detection of associated stages of erosion are of clear importance in modern Earth sciences and in their application.

A comparably wide set of papers was devoted to the Apennines of Italy. A large scale discussion of the Apennine system is presented by Tozer et al. who compare two quite different visions of Apennine shortening depending on basement involvement. Mazzoli et al. present a contribution on relations between sedimentation and thrusting in the external zones of the Apennines. These transitional areas are often of major importance in recording the interactions between colliding plates. Basins developing in the external parts of the Apennine collisional orogen are investigated and interpreted by Di Grande and Giandinoto.

One paper is dedicated to the Dinarides, thereby covering most European orogens. In her contribution, Tari integrates a very large and mainly unpublished data base to present a regional crustal section across the Dinarides, one of the most interesting and relatively less known orogens in Europe.

Acknowledgements. We thank all the reviewers for their effort in constructively and thoroughly reviewing the papers submitted to this volume. For the organization of the Meeting we have received substantial help from several persons and Institutions. We would like to thank V. Tolar, O. Lexa and J. Hak (Prague) for their substantial help with organization of the meeting and abstracts volume, P. van Veen, J. Smit, and V. Zampetti (Amsterdam) for their very competent and efficient help in handling registration matters. KNAW, the Royal Academy of Science of the Netherlands and NSG (Netherlands Research School on Sedimentary Geology) are warmly thanked for their financial support. We appreciated the help and enthusiasm of John Cosgrove. Last but not least, we would like to thank all the participants to (UN)COUPLED2000 for their stimulating contributions. This is ISES contribution 2002.0601. 